\title{
THE
}

\section{Numerical Quantification of Perkinsus marinus in the American Oyster Crassostrea virginica (Gmelin, 1791) (Mollusca: Bivalvia) by Modern Stereology}

\author{
Antonio Remacha-Trivino \\ University of Rhode Island \\ Doranne Borsay-Horowitz \\ Christopher Dungan \\ Ximo Gual-Arnau \\ Javier Gomez-Leon \\ University of Rhode Island
}

See next page for additional authors

Follow this and additional works at: https://digitalcommons.uri.edu/favs_facpubs

Terms of Use

All rights reserved under copyright.

\section{Citation/Publisher Attribution}

Remacha-Trivino, A., Borsay-Horowitz, D., Dungan, C., Gual-Arnau, X., Gomez-Leon, J., Vilamil, L., \& GomezChiarri, M. (2008). Numerical Quantification of Perkinsus marinus in the American Oyster Crassostrea virginica (Gmelin, 1791) (Mollusca: Bivalvia) by Modern Stereology. Journal of Parasitology, 94(1), 125-136. doi: $10.1645 / G E-1148.1$

Available at: http://dx.doi.org/10.1645/GE-1148.1

This Article is brought to you for free and open access by the Fisheries, Animal and Veterinary Sciences at DigitalCommons@URI. It has been accepted for inclusion in Fisheries, Animal and Veterinary Sciences Faculty Publications by an authorized administrator of DigitalCommons@URI. For more information, please contact digitalcommons-group@uri.edu. 


\section{Authors}

Antonio Remacha-Trivino, Doranne Borsay-Horowitz, Christopher Dungan, Ximo Gual-Arnau, Javier Gomez-Leon, Luisa Villamil, and Marta Gomez-Chiarri 


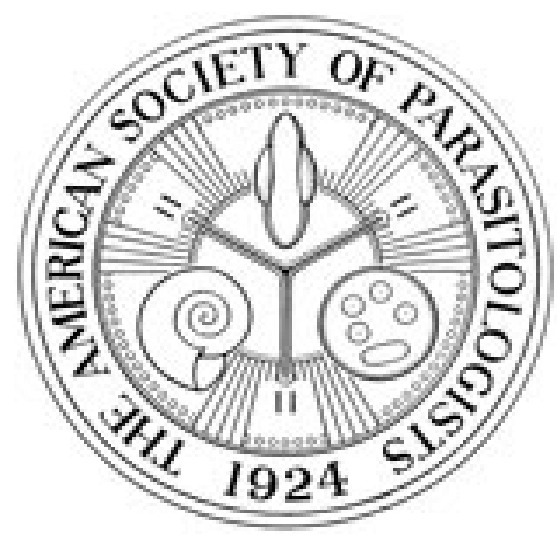

Numerical Quantification of Perkinsus marinus in the American Oyster Crassostrea virginica (Gmelin, 1791) (Mollusca: Bivalvia) by Modern Stereology

Author(s): Antonio Remacha-Triviño, Doranne Borsay-Horowitz, Christopher Dungan, Ximo Gual-Arnau, Javier Gómez-Leon, Luisa Villamil and Marta Gómez-Chiarri

Reviewed work(s):

Source: The Journal of Parasitology, Vol. 94, No. 1 (Feb., 2008), pp. 125-136

Published by: The American Society of Parasitologists

Stable URL: http://www.jstor.org/stable/40058984

Accessed: 04/03/2013 15:15

Your use of the JSTOR archive indicates your acceptance of the Terms \& Conditions of Use, available at http://www.jstor.org/page/info/about/policies/terms.jsp

JSTOR is a not-for-profit service that helps scholars, researchers, and students discover, use, and build upon a wide range of content in a trusted digital archive. We use information technology and tools to increase productivity and facilitate new forms of scholarship. For more information about JSTOR, please contact support@jstor.org.

The American Society of Parasitologists is collaborating with JSTOR to digitize, preserve and extend access to The Journal of Parasitology. 


\title{
NUMERICAL QUANTIFICATION OF PERKINSUS MARINUS IN THE AMERICAN OYSTER CRASSOSTREA VIRGINICA (GMELIN, 1791) (MOLLUSCA: BIVALVIA) BY MODERN STEREOLOGY
}

\author{
Antonio Remacha-Triviño, Doranne Borsay-Horowitz*, Christopher Dungan†, Ximo Gual-Arnauł, Javier Gómez-Leon, \\ Luisa Villamil, and Marta Gómez-Chiarri \\ Department of Fisheries, Animal and Veterinary Sciences, University of Rhode Island, 20A Woodward Hall, Kingston, Rhode Island 02881. \\ e-mail: tonirem@gmail.com
}

\begin{abstract}
Species of Perkinsus are responsible for high mortalities of bivalve molluscs world-wide. Techniques to accurately estimate parasites in tissues are required to improve understanding of perkinsosis. This study quantifies the number and tissue distribution of Perkinsus marinus in Crassostrea virginica by modern stereology and immunohistochemistry. Mean total number of trophozoites were (mean \pm SE) $11.80 \pm 3.91$ million and $11.55 \pm 3.88$ million for the optical disector and optical fractionator methods, respectively. The mean empirical error between both stereological approaches was $3.8 \pm 1.0 \%$. Trophozoites were detected intracellularly in the following tissues: intestine $(30.1 \%)$, Leydig tissue $(21.3 \%)$, hemocytes $(14.9 \%)$, digestive gland $(11.4 \%)$, gills $(6.1 \%)$, connective tissues $(5.7 \%)$, gonads $(4.1 \%)$, palps $(2.2 \%)$, muscle $(1.9 \%)$, mantle connective $(0.8 \%)$, pericardium $(0.7 \%)$, mantle epithelium $(0.1 \%)$, and heart $(0.1 \%)$. The remaining $0.6 \%$ were found extracellularly. Percentages of trophozoite stages were (mean $\pm \mathrm{SE}$ ): large, log-phase trophonts, i.e., signet rings, $97.0 \pm 1.2 \%$; meronts, $2.0 \pm 0.9 \%$; clusters of small, $\log$-phase trophonts, i.e., merozoites, $1.0 \pm 0.5 \%$. Levels of infection in hemocytes and Leydig tissue were representative of total parasite intensity. These techniques are a powerful tool to follow parasite distribution and invasion, and to further explore mechanisms of Perkinsus spp. pathogenesis in bivalves.
\end{abstract}

Species of Perkinsus are responsible for high mortalities of bivalve molluscs worldwide (Villalba et al., 2004). The pathology caused by Perkinsus spp., generally known as perkinsosis, is characterized by infiltration of hemocytes into infected tissues, followed by chronic wasting, impairment of growth, and eventual mortality of the shellfish by emaciation (Ford and Tripp, 1996). To improve the knowledge of the pathogenesis of perkinsosis, accurate techniques to estimate the number of parasites in tissue sections are required (Romestand et al., 2001). Accurate quantification of Perkinsus marinus infections in tissues is essential for understanding the biological interaction between the parasite and its host, including elucidation of portals of entry and mechanisms of disease progression. Present techniques to quantify Perkinsus spp. include (1) visual detection of parasite stages in tissue smears (Stein and Mackin, 1957) and tissue sections (Dungan and Roberson, 1993); (2) assays based on counting hynospores in Ray's fluid thioglycollate medium (RFTM)-incubated tissues from the whole animal (Choi et al. 1989; Bushek et al., 1994; Fisher and Oliver, 1996), tissue subsamples (Ray, 1952), and hemolymph sampling (Gauthier and Fisher, 1990; Nickens et al., 2002); and (3) molecular biology techniques based on detection of DNA or RNA by polymerase chain reaction (PCR; Marsh et al., 1995; Robledo et al., 1998; Yarnall et al., 2000; Audemard et al., 2004; Elandalloussi et al., 2004). However, no current procedures are able to perform accurate quantifications for the number and tissue distribution of total parasites or parasite stages in tissue sections.

Modern stereology is a discipline of wide application in areas of biology and medicine like neurosciences and oncology, among others (Pakkenberg and Gundersen, 1988; Cruz-Orive and Roberts, 1993; Mattfeldt et al., 1993; Roberts et al., 1993,

Received 4 December 2006; revised 2 June 2007; accepted 27 June 2007.

* U.S. Environmental Protection Agency, Atlantic Ecology Division, 27 Tarzwell Drive, Narragansett, Rhode Island 02882.

† Maryland Department of Natural Resources, Cooperative Oxford Laboratory, 904 S. Morris Street, Oxford, Maryland 21654.

‡ Departament de Matemàtiques, Campus Riu Sec, Universitat Jaume I, 8029AP-Castello, Spain.
1994; McNulty et al., 2000; García-Fiñana et al., 2003). Modern stereological methods can be defined as a collection of strongly based mathematical procedures aimed to quantify geometrical properties of target objects without assumptions concerning inherent characteristics of these objects, like size, shape, or distribution. These techniques stem from the concept of accuracy as an additive property of unbiasness and precision. The first modern stereological approaches were developed through the 1980s (Cruz-Orive, 1980; Sterio, 1984). Precedent stereological techniques known as classical methods are assumption-dependent (e.g., Saltykov, 1958).

One of the goals of design-based modern stereology has been the development of new techniques oriented to the unbiased and highly efficient quantification of particles in tissues sections. Among these, the optical disector (OD) (Gundersen, 1986) and the optical fractionator (OF) (West et al., 1991) are considered some of the most reliable approaches.

The present study aims to quantify the number and tissue distribution of different stages of the protozoan parasite $P$. marinus in a natural population of Crassostrea virginica by the application of modern stereology and immunohistochemistry. Immunohistochemistry was used to aid in the detection and quantification of $P$. marinus, since the parasite is difficult to resolve efficiently in tissue sections, particularly in areas of heavy hemocytic infiltration (Choi et al., 1989; Dungan and Roberson, 1993). The information provided by these techniques will be useful to follow parasite distribution and progression in experimental and natural infections, and to further explore mechanisms of pathogenesis.

\section{MATERIALS AND METHODS}

\section{Initial processing of samples}

Eight specimens of $C$. virginica of mean shell height (mean $\pm \mathrm{SD}$ ) of $98.6 \pm 8.5 \mathrm{~mm}$ were harvested intertidally from Cedar Tree Point (Wickford, Rhode Island) in July 2005. Oysters were maintained for 24 $\mathrm{hr}$ in a 50-L filtered tank filled with artificial seawater at $25 \mathrm{C}$ and $27 \%$ salinity. 


\section{Extraction of the meat}

Stereological approaches applied here require maintenance of the original conformation and perfect condition of the whole tissues. Therefore, oyster meats, including the boundaries between mantle and adductor muscle and the edges of the latter, were extracted intact by gently wedging the valves to open a narrow access without affecting the soft tissues, and detaching the edges of the adductor muscle with a spatula.

\section{Estimation of the volume of the meat}

Gravimetric estimations: A container large enough to prevent overflows was placed on a precision balance, filled partially with filtered artificial seawater, and weighed to the closest milligram before performing the immersion of each oyster meat mass. Meats were drained on filter paper for $2 \mathrm{~min}$, held by a fine thread attached to the adductor muscle, and submerged into the container. After a complete immersion without meat contact with container walls, container and meats were weighed to the closest milligram. The density of the immersion fluid was estimated to the closest milligram from the average weight of 10 replicates of $100 \mathrm{ml}$. Meat mass (mtm) volumes were estimated gravimetrically according to Scherle's (1970) method.

$$
\hat{V}(\mathrm{mtm})=\frac{W_{2}-W_{1}}{\rho}
$$

where $\hat{V}(\mathrm{mtm})$ is the meat mass volume (note that symbol "^" is used to distinguish the estimator of the parameter $\hat{V}(\mathrm{mtm})$ from the parameter $V(\mathrm{mtm})$ itself), $W_{2}$ is the weight after the immersion of the meat, $W_{1}$ is the weight before the immersion of the meat, and $\rho$ is the density of the fluid. Next, specimens were preserved in Davidson's AFA fixative (Dungan and Roberson, 1993) for $24 \mathrm{hr}$ and dehydrated in $70 \%$ ethanol for $\mathbf{4 8} \mathrm{hr}$.

Cavalieri estimations: Six-millimeter serial thick sections, or slabs, were obtained by positioning each animal at random within a stereological cutting machine (Michel and Cruz-Orive, 1988; Paché et al., 1993), enrobed in $2 \%$ agar, and sliced exhaustively (Figs. 1, 2). Cavalieri areas were estimated by superimposing a stereological grid of points of $a / p=14.06 \mathrm{~mm}^{2}$ at random on a fixed side of each slab. Cavalieri volumes were obtained according to the point-counting variant of Cavalieri's Principle (Cavalieri, 1635):

$$
\hat{V}(\mathrm{mtm})=T \cdot \frac{a}{p} \cdot M^{-2} \cdot \sum_{i=1}^{n} P_{i}
$$

where $\hat{V}(\mathrm{mtm})$ is the meat mass volume or reference space, $T$ is the mean thickness of the tissue slabs, $a / p$ is the area per point of the points grid, $M$ is the magnification, and $P_{i}$ are the number of points counted in the $i$ th slab.

\section{Embedding, immunostaining, and routine staining}

A systematic subsample of $k=2$ slabs was randomly selected from each animal (Fig. 2a), dehydrated in S-29 reagent (Technicon, Chauncey, New York) for $5 \mathrm{hr}$, cleared in UC-670 clearing reagent (Technicon) for $4 \mathrm{hr}$, infiltrated in Paraplast Xtra and Paraplast Plus (Fisher Scientific, Pittsburgh, Pennsylvania) (50\% each) for $2 \mathrm{hr}$, embedded in the previous Paraplast mixture, and sectioned with a microtome. Forty-micrometer Cavalieri serial sections were mounted on silanized slides, equilibrated in $0.15 \mathrm{M}$ phosphate-buffered saline (PBS), blocked for 75 min, incubated for $75 \mathrm{~min}$ in $12 \mu \mathrm{g} / \mathrm{ml}$ rabbit anti-P. marinus IgG (Dungan and Roberson, 1993), washed in PBS plus $0.05 \%(v / v)$ Tween-20 (PBST), incubated for $75 \mathrm{~min}$ in $4 \mu \mathrm{g} / \mathrm{ml}$ anti-rabbit IgG horseradish peroxidase conjugate (Pierce, Rockford, Illinois), washed in PBST and PBS, stained for 20 min with HistoMark BLACK DAB-cobalt reagent (KPL, Gaithersburg, Maryland), and counterstained for $30 \mathrm{sec}$ with $1 \%$ $(\mathrm{w} / \mathrm{v})$ metanil yellow in $1 \%(\mathrm{v} / \mathrm{v})$ glacial acetic acid. For a parallel monitoring of the pathology by histology, 7- $\mu \mathrm{m}$ serial sections were similarly immunostained and counterstained with eosin Y-phloxine B (Fisher Scientific).

\section{Estimation of the total number of trophozoites}

Parasite trophozoites were counted with the aid of computer-aided stereological toolbox (CAST) grid system (Olympus, Copenhagen, Denmark). This system includes a monitored microscope stage that allows performance of systematic sampling in the $x-y$ plane, avoiding repetitive counts of the same parasite cells within sections. Displacements along the $z$ coordinate are measured with a microcator. The magnification of the CAST grid system, i.e., $\times 4,000$, was high enough to prevent misdetection of trophozoites or to confuse them with histological elements with endogenous peroxidase activity, e.g., mucous cells, or with pigmented oyster cells that may resemble immunostained $P$. marinus cells at lower magnification, e.g., brown cells. Quantification of $P$. marinus was performed by the application of the OD and $O F$.

$O D:$ The numerical density of trophozoites within the reference space was estimated by the OD, whose expression is:

$$
\hat{N}_{V}(\mathrm{tpz}, \mathrm{mtm})=\frac{\sum Q^{-}(\mathrm{tpz})}{\sum\left[a^{\prime}(f) \cdot h(\mathrm{~s}) \cdot P\right]}
$$

where $\Sigma Q^{-(t p z)}$ is the total number of trophozoites counted in the disectors, $a^{\prime}(f)$ is the disector area, $h(s)$ is the disector height corrected for slice thickness, and $P$ are the number of disectors that intersected the meat mass volume $V(\mathrm{mtm})$.

The disector height was corrected for slice thickness shrinkage in each specimen by means of the identity (Cruz-Orive et al., 2002):

$$
h(s)=h \cdot t / t^{\prime}
$$

where $h$ is the theoretical disector height, $t$ is the nominal slice thickness, and $t^{\prime}$ is the final slice thickness after shrinkage (Figs. 2i, j). Finally, the total number of trophozoites was estimated by:

$$
N(\mathrm{tpz})=N_{v}(\mathrm{tpz}, \mathrm{mtm}) \cdot V(\mathrm{mtm})
$$

where $N_{v}(\mathrm{tpz}, \mathrm{mtm})$ is the numerical density of trophozoites estimated by Eq. (3) and $V(\mathrm{mtm})$ is the meat mass volume estimated by Eq. (2). Optical fractionator $(O F)$ : Alternatively, the OF was the second approach used to estimate the total number of trophozoites:

$$
\hat{N}(\mathrm{tpz})=\sum Q^{-}(\mathrm{tpz}) \cdot \prod_{i=1}^{n} f_{i}
$$

where $\Pi f_{i}=a(\mathrm{~s}) \cdot\left[a(f) / a^{\prime}(f)\right] \cdot T^{\prime} / h(\mathrm{~s})$ is the product of sampling fractions, $a(f)$ is the area of the fundamental tile or primary sampling fraction in the plane, $a^{\prime}(f)$ is the area of the unbiased frame or secondary sampling fraction in the plane, $T^{\prime}$ is the mean section thickness or primary sampling fraction for the $z$ coordinate, the $z$ axis being perpendicular to the plane of the slice, $h(\mathrm{~s})$ is the disector height corrected for slice thickness by Eq. (4) or third sampling fraction for the $z$ coordinate, and $a(s)$ is the areal shrinkage or rate of retraction in the plane, which was estimated as follows:

$$
a(\mathrm{~s})=\sum_{i=1}^{n} P_{i} / \sum_{j=1}^{n} P_{j}
$$

where $\Sigma P_{j}$ are the number of points counted in the Cavalieri surface of the $j$ th $40-\mu \mathrm{m}$ section, with a points grid of the same sampling intensity as that corresponding for $\Sigma P_{i}$ (Figs. $2 \mathrm{~b}, \mathrm{~d}$ ).

The practical procedure for counting $\Sigma Q^{-}($tpz) is presented in Figures $2 \mathrm{j}, 3 \mathrm{a}-\mathrm{h}$.

\section{Estimation of trophozoite stages within different tissues}

Percentages of trophozoite stages, i.e., log-phase trophonts, including signet rings, meronts, and clusters of small, log-phase trophonts, i.e., merozoites, and percentages of total trophozoites within the following tissues: intestine, Leydig tissue, hemocytes, digestive gland, gills, connective tissues, gonads, palps, muscle, mantle connective, pericardium, mantle epithelium, and heart, were estimated by applying Eq. (6) to each corresponding subsample.

\section{Practical implementation}

Systematic slicing: Oysters meats were sliced into 6-mm slabs (Figs. 1a, b). Systematic sampling can be performed bidirectionally and excludes the first slab, i.e., edge of the oyster, as it lies before the random start (Fig. 2a). All slabs were used for Cavalieri, except the first one.

Cavalieri approach: A points grid was positioned and rotated at random over a fixed face of each slab, i.e., Cavalieri surface, and relevant areas were estimated by point counting. The total number of points counted in a single slab was $\Sigma P_{i}$ (Fig. 2b). Cavalieri areas were estimated according to Eq. (2).

Systematic subsampling and embedding: One of the 2 possible $k=$ 


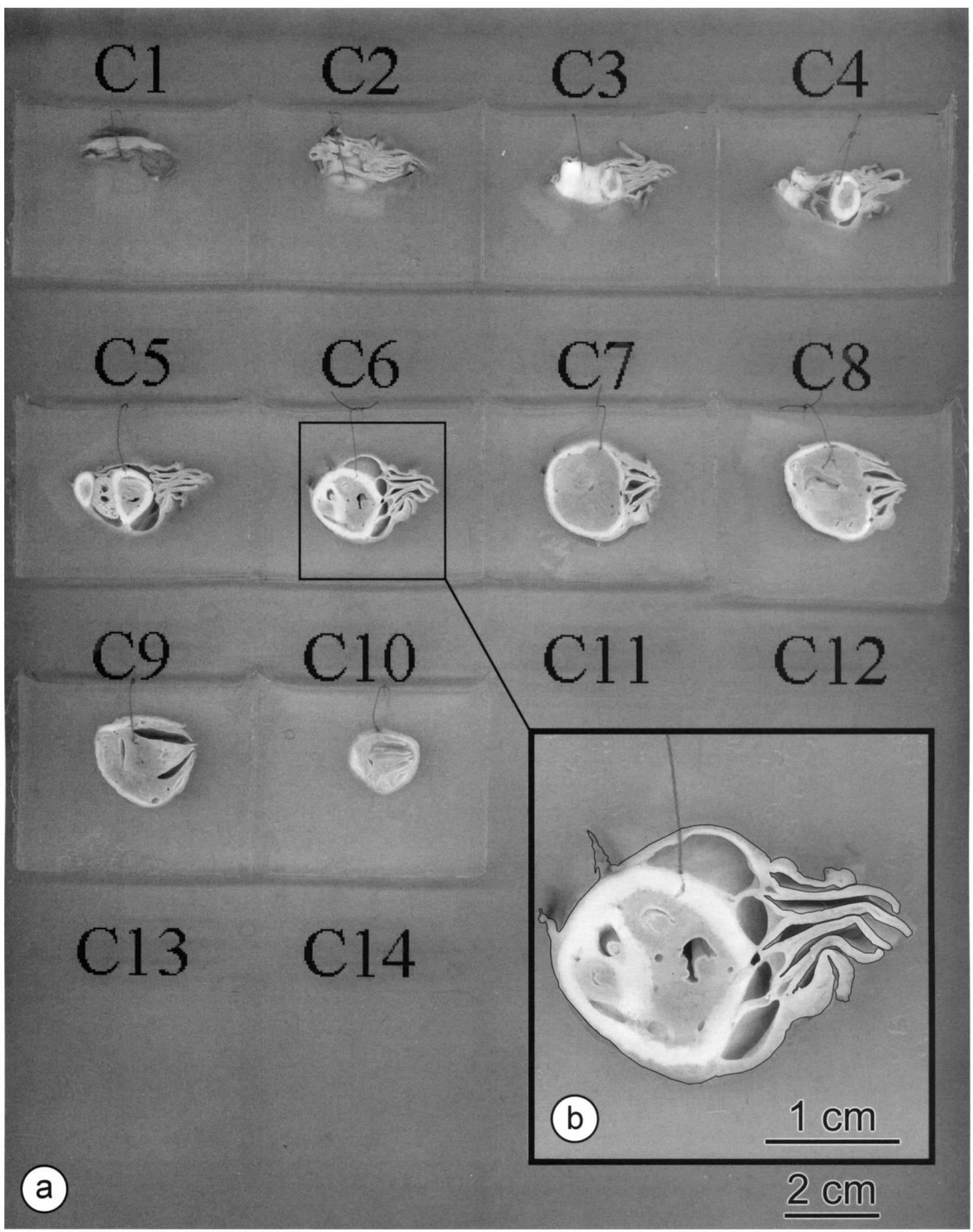

FIGURE 1. (a) Cavalieri sections of $C$. virginica. (b) Detail of C6 displaying the boundaries of the reference area chosen for the approach of Cavalieri. Boundaries were selected to provide the closest reference space to the gravimetric probe, i.e., Scherle's approach. In consequence, the reference space was bounded by the outer surfaces of mantle, gills, and palps. 


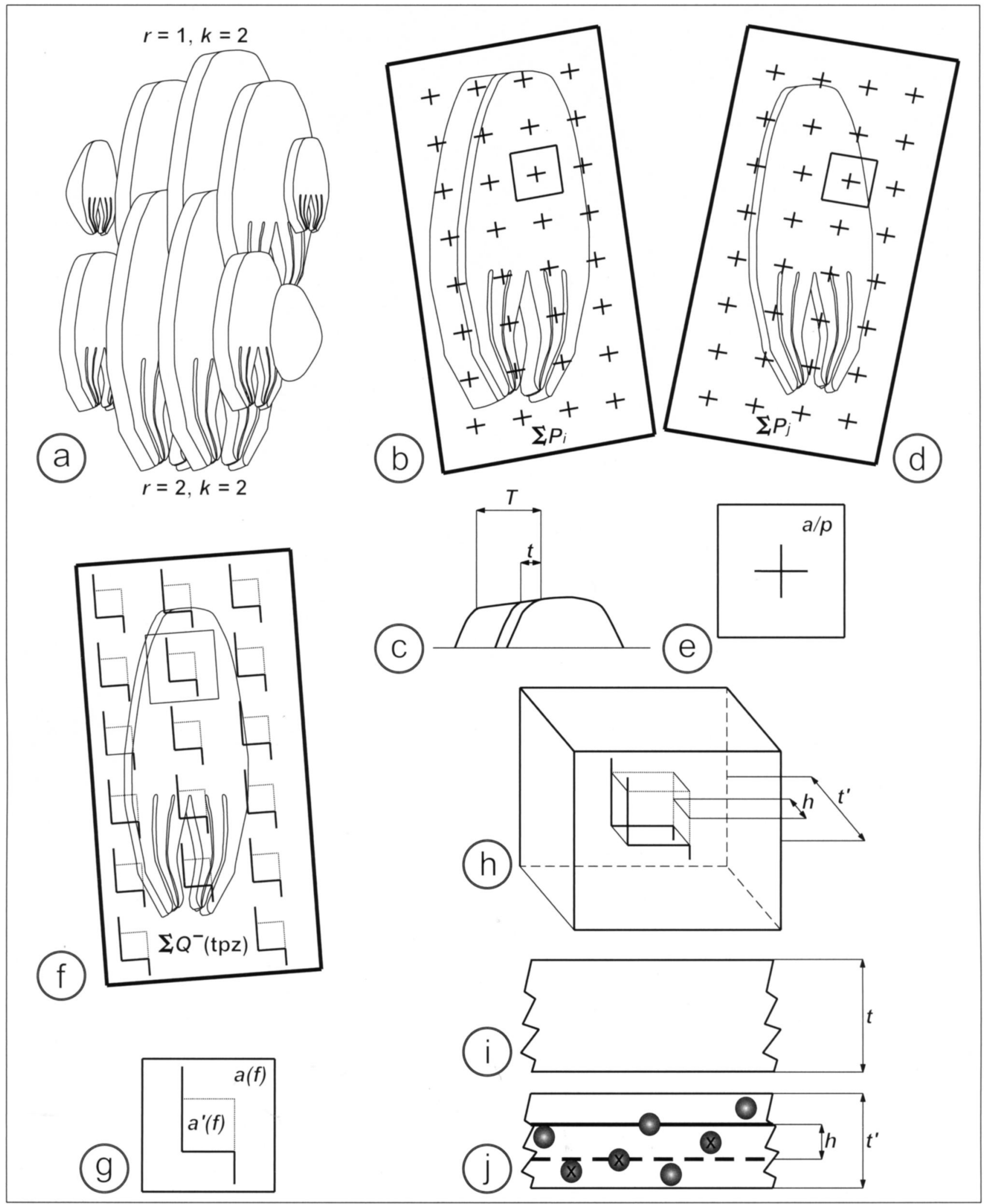

FIGURE 2. Scheme of the stereological design. (a) Random selection of $k=2$ systematic sample after serial sectioning. (b) Estimating Cavalieri areas by point counting. (c) Sampling fraction $T / t$. (d) Estimating the areal shrinkage for the OF by point counting. (e) Sampling fraction $a / p$. (f) Counting trophozoites using a systematic grid of disectors. (g) Sampling fraction $a(f) / a^{\prime}(f)$. (h) Tridimensional view of the optical disector probe within a cube of tissue. (i) Microtome thickness $t$ before shrinkage. (j) Section thickness $t$ ' after shrinkage. Three objects marked with " $X$ " are counted in the example. $h$, theoretical disector height. $\Sigma P_{i}$, points counted in the $i$ th slab, $\Sigma P_{j}$, points counted in the $j$ th thick section, $\Sigma Q^{-}(\mathrm{tpz})$, trophozoites counted in the $j$ th thick section. 

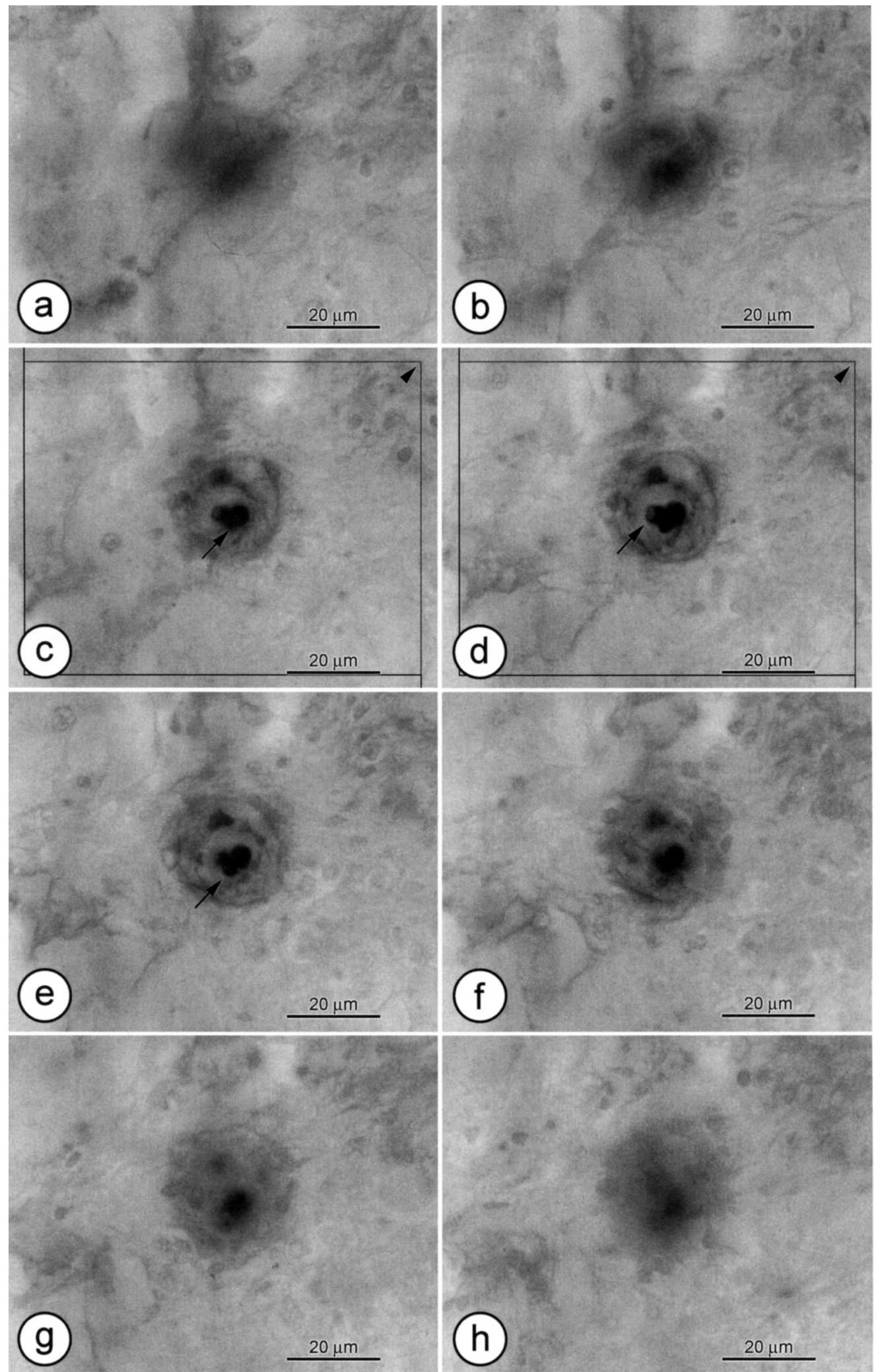

FIGURE 3. Succession of consecutive focal planes in Leydig tissue displaying how the quantifications of trophozoites of $P$. marinus were performed. Countings were made in the central $25 \mu \mathrm{m}$ (theoretical disector height) of the $40-\mu \mathrm{m}$ thick section; the region where the unbiased probe, i.e., OD, appears (c and d). Two trophozoites were counted in this example. Arrows show the trophozoites in focus. Arrow points show the unbiased frame. 
2 systematic samples $(r=1$ or $r=2$ ) was subsampled at random (Fig. $2 a)$. Slabs were embedded, cut into $40-\mu \mathrm{m}$ thick sections, and immunostained.

Concept of sampling fraction: A sampling fraction is a dimensionless ratio derived from dividing an $\boldsymbol{n}$-dimensional predefined total sampling space, e.g., slab thickness $T$, by its space sampled, e.g., slice thickness $t$ (Fig. 2c). The ratio $T / t$ was the first sampling fraction of the stereological design for OD and OF.

Estimating the areal shrinkage by point counting (used in OF exclusively): The $40-\mu \mathrm{m}$ Cavalieri section and its estimated area were obtained from the same slab and grid used in Figure $2 b$. The slab and points grid of Figure $2 \mathrm{~b}$ were used, respectively, to get the corresponding $40-\mu \mathrm{m}$ section and to estimate its area. The total number of points counted in a single thick section was $\Sigma P_{j}$. The section profile of Figure $2 \mathrm{~d}$ is smaller than Figure $2 \mathrm{~b}$ because of the shrinkage effect. The sampling fraction of each points grid $a / p$ was derived from dividing the total sampling space or fundamental tile area $a$ by the point $p$ or sample event (Fig. 2e).

Counting trophozoites: CAST grid system overlaid a systematic grid of disectors within the central $25 \mu \mathrm{m}$ of the thick sections (Fig. 2f). The sampling fraction $a(f) / a^{\prime}(f)$ for the OD and OF stemmed from dividing the fundamental tile area $a(f)$ by the unbiased frame area $a^{\prime}(f)$ (Fig. 2g).

Estimating the thickness shrinkage: The section thickness $t$ before shrinkage was given by the microtome thickness. The section thickness $t^{\prime}$ after shrinkage was measured with CAST grid between the first and last focal planes of the mounted thick section, and $h$ was the theoretical disector height $(25 \mu \mathrm{m}$, Fig. 2i, j).

Practical rule for counting objects by the $O D$ probe: The $O D$ probe (shown in Fig. $2 \mathrm{~h}$ within a cube of tissue) is a tridimensional probe that combines 2 different unbiased rules for counting objects: disector rule (Fig. $2 \mathrm{j}$ ) and unbiased frame rule (Fig. 3c, d).

Disector rule: Upper and lower edges of the OD probe are intersected by a disector, which consists in 2 parallel planes, the acceptance plane, i.e., dashed line, and the rejection plane, i.e., continuous line. Objects are counted when they touch the acceptance plane or lie within the OD probe without touching the rejection plane. Three objects marked with " $X$ " are counted in the example of Figure $2 j$.

Unbiased frame rule: The unbiased frame is formed by 2 types of lines, forbidden lines and counting lines. Forbidden lines are thicker lines whose ends are prolonged to the infinite (Figs. 2g, 3c, d), whereas counting lines are thinner, i.e., shown either in dashed lines in Figure $2 \mathrm{~g}$ or in gray in Figure $3 \mathrm{c}$, d. Trophozoites are counted when they are in focus lying either within the unbiased frame and the OD probe or touching the acceptance plane of the disector and counting lines of the unbiased frame, but without touching either the rejection plane of the disector or the forbidden lines of the unbiased frame. Two trophozoites were counted in the example of Figure 3. Parasite density $N_{v}(\mathrm{tpz}, \mathrm{mtm})$ was obtained by Eq. (3) for OD. Finally, the total number of parasites and parasite stages within tissues were estimated by Eq. (5) for OD and by Eq. (6) for OF.

\section{Numerical example}

In this section, we present a numerical example on the calculations involved in the different stereological approaches used for 1 oyster. Our objectives are to estimate: (1) the meat volume by Cavalieri's Principle; (2) the total number of trophozoites by the OD; and (3) the total number of trophozoites by the $\mathrm{OF}$.

1. The number of points counted in the 10 sections were, respectively, $\left\{P_{i}, i=1, \ldots, 10\right\}=\{5,9,9,16,20,23,25,25,22,13\}$, the sample total being $\Sigma P_{i}=167, \hat{\bar{T}}=6.15 \mathrm{~mm}$ and $a / p=14.06 \mathrm{~mm}^{2}$. The magnification was $M=1$ as point countings were performed at the real scale. Therefore, applying Eq. (2), the meats volume was $\hat{V}(\mathrm{mtm})=6.15 \times 14.06 \times 1^{-2} \times 167=14,440.32 \mathrm{~mm}^{3}$

2. The total number of trophozoites counted was $\Sigma Q^{-}($tpz $)=140$, using $\Sigma P=2,159$ disectors. The area of the sampling frame was $a^{\prime}(f)=3,246 \mu \mathrm{m}^{2}$ and the height of the disector corrected for the shrinkage was $h(\mathrm{~s})=29.34 \mu \mathrm{m}^{3} . h(\mathrm{~s})$ was stemmed from a theoretical disector height $h=25 \mu \mathrm{m}$, a nominal slice thickness $t=40$ $\mu \mathrm{m}$, and a final slice thickness after shrinkage $t^{\prime}=34.08$. By applying Eq. (3), the numerical density of trophozoites was $\hat{N}_{v}(\mathrm{tpz}, \mathrm{mtm})$ $=140 \times(2,159 \times 29.34 \times 3,246)^{-1}=680.87$ cells $\cdot \mathrm{mm}^{-3}$. Finally,

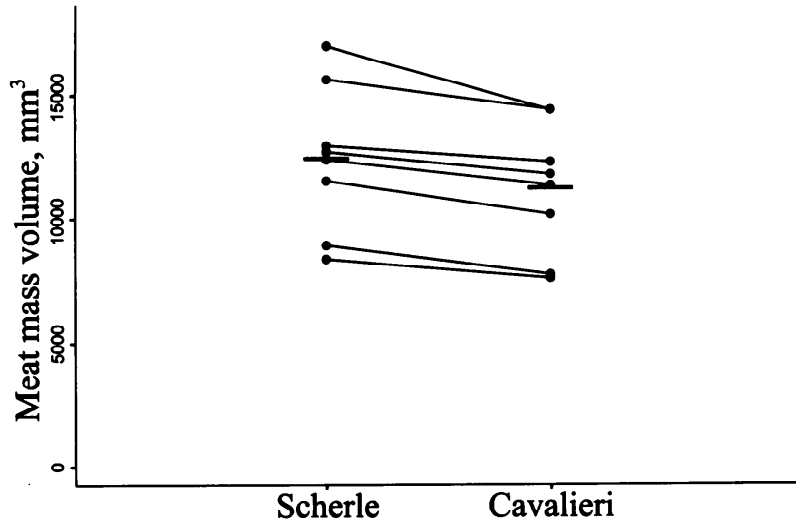

FIGURE 4. Meat volumes of $C$. virginica estimated by the Cavalieri's Principle and Scherle's method. Means for each method are shown by horizontal bars. Estimates for the same oyster are connected by a line.

using Eq. (5) we estimated a total number of 9,831,981 trophozoites in the tissues of this oyster.

3. The number of trophozoites counted were $\Sigma Q^{-}(\mathrm{tpz})=140$. The sampling fraction was $a(f) / a^{\prime}(f)=156.25$. The systematic subsample of $r, k=(2,2)$, where $r \in(1, k)$ is a random number and $k$ is the sampling period, yielded the point counts $\left\{P_{i}, i=2, \ldots, 10\right\}$ $=\{9,16,23,25,13\}$, the sample total being $\Sigma P_{i}=86$; point counts in the $40-\mu \mathrm{m}$ sections were, respectively, $\left\{P_{j}, j=2, \ldots, 10\right\}=$ $\{10,17,21,20,9\}$, the sample total being $\Sigma P_{j}=77$. The areal shrinkage was $a(\mathrm{~s})=\Sigma P_{i} / \Sigma P_{j}=1.12$ and $\hat{\bar{T}}^{\prime}=2 \hat{\bar{T}}=12,300 \mu \mathrm{m}$. $\hat{\bar{T}}$ doubles $\hat{\bar{T}}$ as the Cavalieri period $K=1$ halves the systematic subsample period $K=2$. Therefore, by Eq. (6), the estimate of the total number of parasites was $\hat{N}(\mathrm{tpz})=140 \times 1.12 \times(156.25 \times$ $\left.12,300 \times 29.34^{-1}\right)=10,270,961$ trophozoites. The empirical error between these 2 estimates for the total number of trophozoites was $4.27 \%$.

\section{Correlations and allometric models}

The following relationships: (1) total number of parasites versus number of parasites in the most infected tissues, i.e., intestine, hemocytes, and Leydig; (2) number of parasites between these most infected tissues; and (3) number of parasites between the most representative parasites stages, i.e., signet rings, tomonts, and meronts, were investigated by applying least-squares linear regression models or by alternative common least-squares linear transformations of $(x, y)$ and $(x+1, y+1)$, i.e., semilogarithmic, logarithmic, semiarctangent, and arctangent. Significant correlations and regressions were investigated. Significant regressions were established as allometric models.

\section{RESULTS}

\section{Comparisons between Scherle's method and Cavalieri's Principle}

Paired comparisons corresponding to the oyster meat volumes obtained by Scherle's and Cavalieri's approaches are presented in Figure 4. Scherle's valuations were higher than Cavalieri's estimations in all the specimens. The mean empirical error between both techniques expressed in percentages was (mean $\pm \mathrm{SD}) 10.2 \pm 3.7 \%$.

\section{Number of parasites and parasite stages}

Mean numbers of trophozoites for the 8 oysters analyzed in this study were (mean \pm SE) $11.80 \pm 3.91$ million and 11.55 \pm 3.88 million for the OD and OF methods, respectively (Fig. 5). The mean empirical error between both stereological approaches was $3.8 \pm 1.0 \%$. Trophozoites were detected intra- 


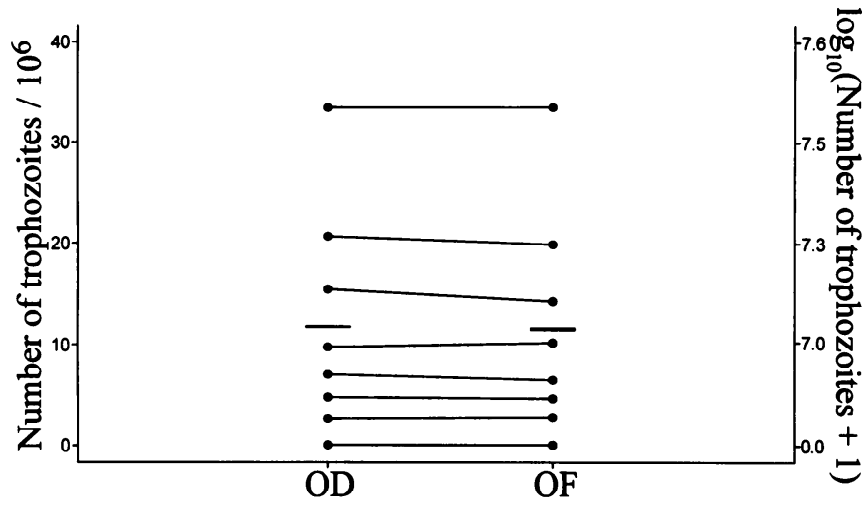

FIGURE 5. Total number of trophozoites of $P$. marinus in $C$. virginica estimated by the OD and the OF. Means for each method are shown by horizontal bars. Estimates for the same oyster are connected by a line.

cellularly in the following tissues: intestine (30.1\%) (Fig. 6a); Leydig tissue $(21.3 \%$ ) (Figs. $6 \mathrm{~b}, \mathrm{c})$; hemocytes in sinuses, vessels, and tissues (14.9\%) (Fig. 6d); digestive gland (11.4\%) (Fig. 6e); gills (6.1\%); connective tissues (except Leydig and mantle) (5.7\%); gonads (4.1\%) (Fig. 6f); palps (2.2\%); muscle (1.9\%); mantle connective $(0.8 \%)$; pericardium $(0.7 \%)$; mantle epithelium $(0.1 \%)$; and heart $(0.1 \%)$. The remaining $0.6 \%$ of the trophozoites were found extracellularly throughout different tissues (Fig. 6g). Brown cells were clearly distinguished from parasites by their different appearance and the endogenous pigmentation of the ceroid bodies (Fig. $6 \mathrm{~h}$ ).

Percentages of trophozoite stages were (mean \pm SE): large, log-phase trophonts, i.e., signet rings, $97.0 \pm 1.2 \%$; meronts, $2.0 \pm 0.9 \%$; clusters of small, log-phase trophonts, i.e., merozoites, $1.0 \pm 0.5 \%$. We were unable to count the individual merozoite cells within clusters because of their small size. Furthermore, because of the low numbers of meronts and merozoites compared with trophozoites, we did not evaluate the relative abundance of these stages in different tissues.

\section{Correlations and allometric models}

The following significant correlations were detected: (1) $\log _{e}$ (total number of trophozoites) versus $\log _{e}$ (trophozoites in Leydig tissue) $\left(P=0.027, r^{2}=0.67\right)$ (Fig. 7a); and (2) total number of trophozoites versus trophozoites in hemocytes $(P=$ $0.016, r^{2}=0.64$ ) (Fig. 7b). In contrast, no significant regressions $(P>0.05)$ or contradictions to regression model assumptions were found between (1) total number of trophozoites versus trophozoites in intestine; (2) trophozoites in intestine versus trophozoites in Leydig tissue; (3) trophozoites in intestine versus trophozoites in hemocytes; (4) trophozoites in Leydig tissue versus trophozoites in hemocytes; (5) total number of tomonts versus total number of signet rings; (6) total number of clusters of merozoites versus total number of signet rings; and (7) total number of clusters of merozoites versus total number of tomonts. The total number of tomonts and clusters of merozoites showed a positive trend (with the exception of the outlier 20.4 $\times 10^{6}$ signet rings, 0 tomonts) with respect to the total number of signet rings.

As a result, the subsequent allometric models were found:

$$
P=0.83 L+4.25
$$

where $P$ and $L$ are the napierian (by 1 ) logarithms of the total number of trophozoites and trophozoites in Leydig tissue, respectively.

$$
T=5.83 H+10^{6.64}
$$

where $T$ is the total number of trophozoites and $H$ is the number of trophozoites in hemolymph.

\section{DISCUSSION}

We have shown here that the application of modern stereological techniques in combination with immunohistochemistry allows for the quantification and assessment of the tissue distribution of the trophozoites of $P$. marinus in naturally infected oysters. The use of an antibody-based differential staining to detect the parasite in tissue sections has proven to be decisive for the accurate detection of the parasite. Nevertheless, modern stereological approaches undoubtedly played the main role in the process of quantification by applying unbiased probes combined with unbiased, efficient, rational, and objective protocols of sampling in which the researcher has complete control of each step of the sampling scheme. The perspective of techniques of modern stereology is radically different from computer methods of image analysis oriented to perform counts of objects automatically by complex mathematical algorithms (Young et al., 1998; Malpica et al., 2002). These methods of image analysis generally fail in common histological situations, like cases of cellular superposition, variations in the staining intensity or affinity among specimens or tissue portions, gradient staining, etc. In modern stereology, the counting is performed by the human eye, the best tool for identifying target objects accurately. In addition, errors derived from the estimations can be predicted mathematically, as the sampling process is unbiased (e.g., Howard and Reed, 1998). Likewise, the accuracy of the modern stereological methods applied here was shown for the total number of parasites, whereas the mean empirical error between the OD and the OF was negligible, i.e., less than a $4 \%$.

When comparing the 2 methods that we used to estimate the meat volumes of the oysters, Scherle's valuations were consistently higher than Cavalieri estimations in all the specimens. Scherle's (1970) method has been thoroughly proved to be the most accurate gravimetric approach to determine the volume of bounded objects (Scherle, 1970; Weibel, 1979; Roberts et al., 1993). However, since this gravimetric probe is a function of the difference in weight of the object submerged in a constant volume of liquid with respect to the aforementioned fluid volume, inaccuracies are expected when objects to be evaluated release or absorb fluids during the process of immersion in the valuation fluid. Although meats of oysters were blotted on filter paper for short intervals to capture excess liquid, a flow of fluid from meats to the peripheral gravimetric liquid was observed from all the different soft parts while immersed, as an obvious consequence of the faculty of bivalve tissues to absorb and release fluids, as well as from bleeding precipitated by even the most careful excision of oyster adductor muscles from their anchoring valve myostraca. These observations may explain why Scherle's valuations were higher than Cavalieri estimations. Regardless of the differences in the estimates for oyster volumes between the 2 methods, those differences were con- 


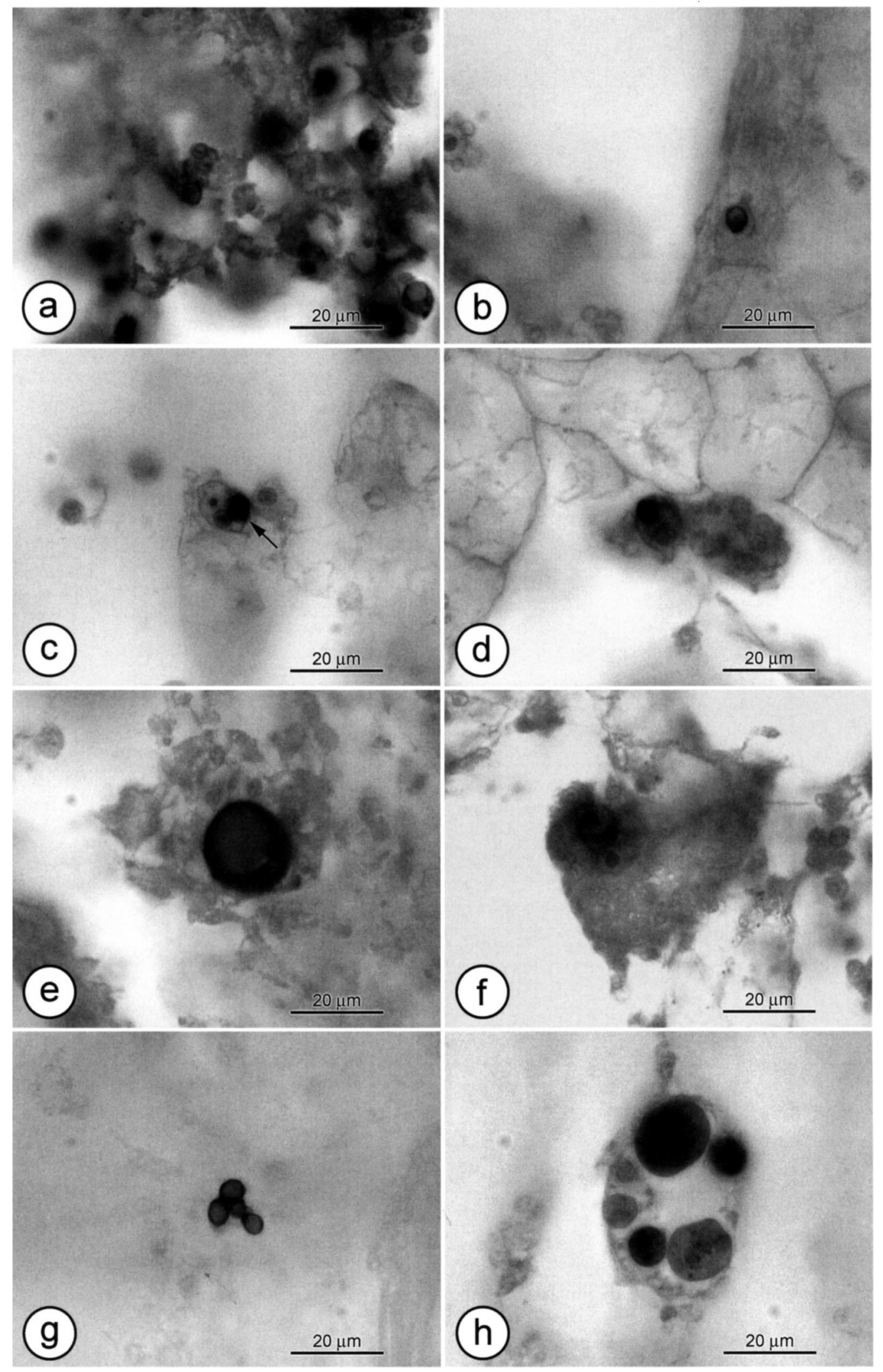

FIGURE 6. Detection of $P$. marinus in tissues of $C$. virginica. (a) Advanced infection in intestine. (b) Perkinsus marinus signet ring in vascular vessel wall. (c) Trophozoite adjacent to nucleus of Leydig cell. (d) Trophozoite inside hemocyte within the Leydig tissue. (e) Extracellular signetring trophozoite in digestive gland. (f) Trophozoite inside oocyte. (g) Free signet-ring trophozoites in pericardial cavity. (h) Brown ceroid cells with multiple ceroid bodies. 

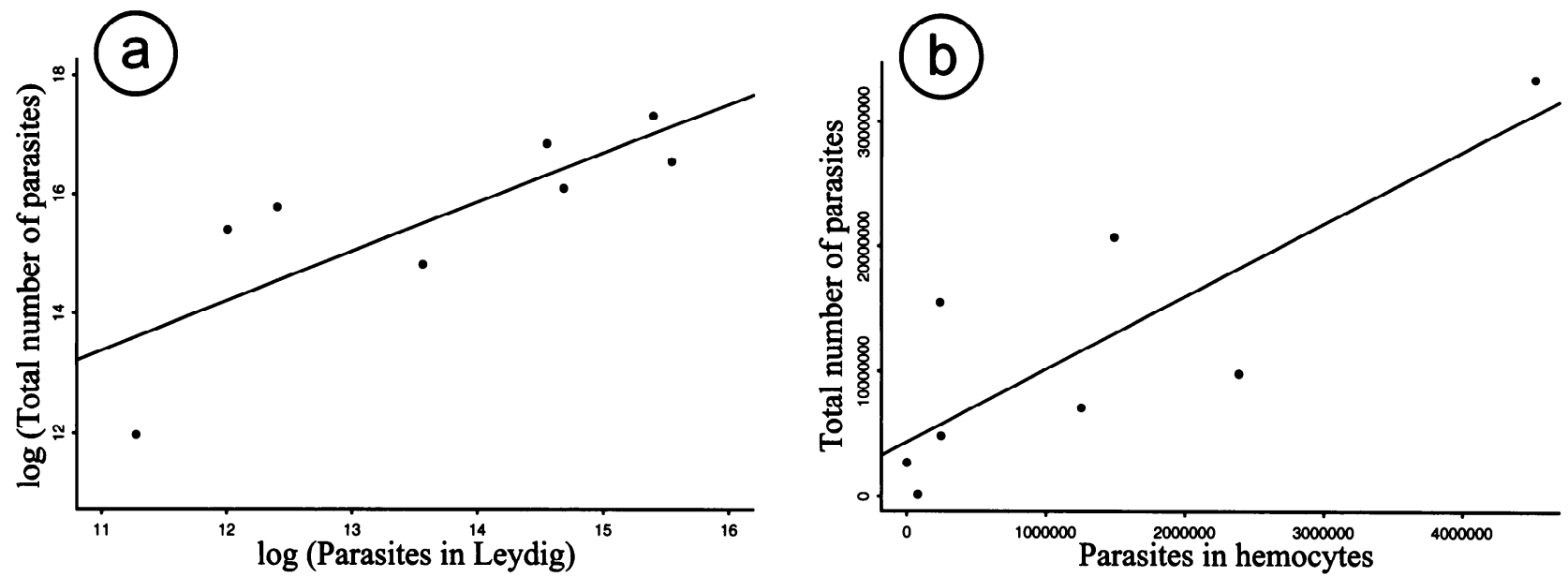

FIGURE 7. Scatter plots and linear regressions of significant numerical relationships of $P$. marinus in tissues of $C$. virginica. (a) $\log _{e}$ (total number of parasites) versus $\log _{e}$ (parasites in Leydig tissue). (b) Total number of parasites versus parasites in hemocytes.

sistent between individual oysters, suggesting that the application of Scherle's approach for performing rapid and approximated valuations of meat volumes in oysters is appropriate.

A relevant aspect of the stereological design concerns the correspondence of reference spaces in the estimation of the total number of trophozoites in Eq. (5). For the estimations to be correct, the reference spaces from $40-\mu \mathrm{m}$ sections analyzed with CAST grid have to be bounded using the same criteria applied to the 6-mm Cavalieri sections. To do so, all the internal spaces of meats with or without Perkinsus are included in both reference spaces. Because Cavalieri volumes were estimated before the embedding, the areal shrinkage must not be corrected in OD. Inclusion of the internal spaces devoid of $P$. marinus cells is irrelevant because both reference volumes are equal in Eq. (5). However, empirical differences between both reference volumes (including the empty cavities) must be contrasted. The correspondence between both Cavalieri and density volumes is demonstrated by comparing the results from the $\mathrm{OD}$ and $\mathrm{OF}$, because the latter approach lacks of reference volumes. In this account, the relatively small empirical error between these 2 methods for each oyster validates our results.

Stereological methods have been widely applied to bivalve mollusc research, especially in studies that estimate fecundity by counting the number of oocytes (e.g., Bayne et al., 1978; Lowe et al., 1982; Newell et al., 1982; Sundet and Lee, 1984; Pipe, 1985; Beninger, 1987; Morvan and Ansell, 1988; Paulet et al., 1992; Pazos et al., 1996). However, most of these techniques are not modern stereological procedures and none of them is an optical method. These classical approaches (e.g., Saltykov, 1958), commonly known as unfolding techniques, are not recommended because they are subjected to errors derived from assumptions concerning the size, shape, or distribution of the target particles, which were demonstrated when applied to cells to give rise to results too unrealistic to be scientifically accepted (see Mayhew and Gundersen, 1996). In bivalves, Cavalieri's Principle, OD, OF, and their respective formulas for predicting theoretical errors were applied to Solen marginatus ( $\mathrm{Re}$ macha-Triviño, 2002) to estimate hemocyte numbers in kidney tissues. Expressions of these theoretical errors were updated for Cavalieri's Principle to estimate oocyte numbers by the physical disector in a single specimen of Tapes pullastra (Alvarez and Gual-Arnau, 2006). The main advantage of the optical procedures used in our work (OD and OF) with respect to precedent physical methods (Sterio, 1984; Gundersen, 1986) is that particles are counted in a succession of focal planes without losing any information between the 2 disector physical planes, as well as an optimal preservation of the target tissues. To ensure optimal preservation of the tissues, quantifications performed by the $O D$ and the $O F$ require leaving a region free of counting ( $7.5 \mu \mathrm{m}$ in our case) at both sides of the $40-\mu \mathrm{m}$ thick sections. This gives rise to quantifications free of errors related to losses of tissue removed from the edges of the sections, a well-known phenomenon derived from the combined action of the microtome blade and the different chemical agents supplied for sampling, processing, and embedding (see Andersen and Gundersen, 1999).

One of the additional requirements of the OD and OF is that the target objects to be counted must be small enough to be assumed as points, or alternatively, to associate a point to each target object to be counted. Otherwise, quantifications would depend on the size of particles. Therefore, the practical rule to quantify populations of cells is generally based on counting a fixed part of the cell, e.g., upper part of the nucleolus or nucleus, which can be identified in every cell, at 1 unit per cell, and small enough to be counted as it comes into focus. In the case of $P$. marinus, the protozoan stages of this study matched the maximum size of $16 \mu \mathrm{m}$ in cellular diameter described for cultured $P$. marinus (Sunila et al., 2001), dimensions small enough to be clearly identified by their first focal plane as they come into focus.

In general, optical methods can be applied to convex objects, as is the case of the spheroid trophozoites investigated here, but excludes particles whose conformation could give rise to errors in their identification, e.g., ramified cells like neurons. However, nonconvex and ramified objects can also be counted by OD and $O F$ if they are small enough to be observed sequentially in all of their focal planes within the limits of the screen in whichever position they intersect the OD probe. This second variant resembles serial sectioning as it requires scanning all the different 
parts of the objects to guarantee their right quantification; whereas it is not restricted to particular geometries.

Another challenge to the use of stereology to detect parasites in tissue sections stemmed from the fact that $P$. marinus is distributed in aggregates (Chintala et al., 2002). The heterogeneous presence of the protozoan within tissues and oysters required a sampling design focused on increasing the sampling intensity at the level of the sections to give rise to a sampling fraction $a^{\prime}(f) / a(f)$ of $0.64 \%$ in oysters with less than 20 million parasites, and $0.32 \%$ for the rest of the specimens.

In addition to applying modern stereological methods for the quantification of Perkinsus spp. parasites in oysters, this work provides useful information regarding perkinsosis in American oysters. Our observations showing the highest densities of the parasite in the intestine and Leydig tissue of naturally infected oysters contrast with the findings of previous researchers who observed the highest densities of $P$. marinus in the digestive gland (Mackin, 1951; Choi et al. 1989; Fisher and Oliver et al. 1996). However, they are consistent with results from several experimental infections that point to the important role of the connective tissue and the hemocytes in the proliferation and transport of $P$. marinus in oysters (Chintala et al. 2002).

Interestingly, the lack of correlation between the number of parasites in the intestine and the total number of parasites in the oyster indicated that the degree of infection in intestine is not representative of the overall levels of infection in oysters. On the contrary, the degree of infection in Leydig tissue and hemocytes was shown to be more representative of perkinsosis intensity in $C$. virginica. This indicates that the infection in intestine is asynchronous with respect to the spread of the parasite in the rest of the tissues, suggesting that results of RFTMbased tissue assays from hemolymph and Leydig tissue may be more accurate than assays using intestinal tissue. In this regard, it is important to mention that Leydig tissue and hemolymph are some of the most frequent and homogenously distributed tissues in the oyster.

When compared with the modern stereological methods applied here, procedures traditionally used to quantify $P$. marinus show several disadvantages. First, observations from histological, immunohistochemical, tissue RFTM, or molecular assays are based on partial samplings. Therefore, extrapolations of subsample results to the whole animal are subject to error. Second, RFTM methods are focused on enumerations of a unique cell type, the hypnospore, after enlargement of different stages of $P$. marinus in culture media (Ray, 1954), and do not provide information on the relative abundance of the different parasitic stages. Third, RFTM methods applied to the whole animal, i.e., whole body burdens (Choi et al., 1989; Bushek et al., 1994; Fisher and Oliver, 1996), are based on the assumption of considering a $100 \%$ enlargement and survival of the hypnospores in the culture media. However, an unknown rate of mortality or lysis of weaker trophozoites and hypnospores during their enlargement in RFTM may occur. In this sense, Nickens et al. (2002) reported that simple modifications of the RFTM medium, including the addition of 5\% lipid concentrate, resulted in larger hypnospores, indicating that the enlargement of $P$. marinus in RFTM may not be optimal. Fourth, molecular biology approaches on the basis of PCR amplification of extracted DNA subsamples to detect or quantify $P$. marinus DNA (Marsh et al., 1995; Robledo et al., 1998; Yarnall et al., 2000; Penna et al., 2001; Audemard et al., 2004; Elandalloussi et al., 2004; Gauthier et al., 2006) have both sampling errors, as well as potential detection of DNA from nonviable cells (MDTAO, 2003). Moreover, the unknown effects of the procedures for DNA isolation and purification on yield and the presence of contaminants or PCR inhibitors in the tissue samples must be considered and mitigated.

The stereological methods applied here, however, showed some limitations with the OD and the OF failed in counting the following parasite stages: (1) trophozoites located in hemocytes lost during phases of processing and embedding; (2) extracellular trophozoites lost similarly due to processing and embedding; (3) merozoites within clusters, as these cells were too small to be counted separately and had to be necessarily classified as clusters; and (4) zoospores and free single extracellular or intracellular merozoites, which had to be ignored because they were too small. Nevertheless, all the precedent biases are not due to limitations of the stereological techniques applied here, but to the peculiarities of the life cycle of $P$. marinus.

In summary, the combination of modern stereological techniques with immunohistochemistry has proven to be a useful method to quantify parasites in the tissues of naturally infected oysters. The information provided by these techniques could be useful to follow parasite distribution and progressive invasion in experimental infections, and to further explore mechanisms of pathogenesis. Further combination of modern stereology techniques with immunohistochemistry and histologically based assays of cell viability and apoptosis (Sunila and LaBlanca, 2003) would provide an extremely valuable tool in the investigation of host-parasite interactions.

\section{ACKNOWLEDGMENTS}

This research was supported by Alfonso's Martín Escudero Foundation (Spain) under Grant 2004-2005 for the Specialization in International Universities or Research Centers and USDA CSREES Award 2004-34438-15041.

\section{LITERATURE CITED}

Alvarez, P., AND X. Gual-Arnau. 2006. A quantitative study on gonad fecundity in a native clam (Tapes pullastra) from stereological unbiased estimators. Image Analysis and Stereology 25: 63-110.

Andersen, B. B., AND H. J. G. Gundersen. 1999. Pronounced loss of cell nuclei and anisotropic deformation of thick sections. Journal of Microscopy 196: 69-73.

Audemard, C., K. S. Reece, And E. M. Burreson. 2004. Real-time PCR for detection and quantification of the protistan parasite Perkinsus marinus in environmental waters. Applied and Environmental Microbiology 70: 6611-6618.

Bayne, B. L., D. L. Holland, M. N. Moore, D. M. Lowe, and J. WIDDOws. 1978. Further studies on the effects of stress in the adult on the eggs of Mytilus edulis. Journal of the Marine Biological Association of the United Kingdom 58: 825-841.

Beninger, P. G. 1987. A qualitative and quantitative study of the reproductive cycle of the giant scallop, Placopecten magellanicus, in the Bay of Fundy (New Brunswick, Canada). Canadian Journal of Zoology 65: 495-498.

BusheK, D., S. E. Ford, AND J. K. A. Allen. 1994. Evaluation of methods using Ray's Fluid thioglicollate medium for diagnosis of Perkinsus marinus infection in the eastern oyster, Crassostrea virginica. Annual Review of Fish Diseases 4: 201-217.

Cavalieri, B. 1635. Geometria Indivisibilibus Continuorum. Typis Clementis Feronij, Bononi. Reprinted in 1996 as Geometria degli Indivisibili. Unione Tipografico-Editrice Torinese, Torino, Italy, 870 p.

Chintala, M. M., D. BusheK, AND S. Ford. 2002. Comparison of in 
vitro-cultured and wild-type Perkinsus marinus. II. Dosing methods and host response. Diseases of Aquatic Organisms 51: 203-216.

Choi, K. S., E. A. Wilson, D. H. Lewes, E. N. Powell, and S. M. RAY. 1989. The energetic cost of Perkinsus marinus parasitism in oysters: Quantification of the thioglycollate method. Journal of Shellfish Research 8: 125-131.

CRUZ-ORIVE, L. M. 1980. On the estimation of particle number. Journal of Microscopy 120: 15-27.

- A. M. Insausti, R. Insausti, AND D. Crespo. 2002. A case study from neuroscience involving stereology and multivariate analysis. In Quantitative methods in neuroscience, S. M. Evans, and J. R. Nyengaard (eds.). Oxford University Press, Oxford, U.K., p. $16-64$

- AND N. ROBERTS. 1993. Unbiased volume estimation with coaxial sections: An application to the human bladder. Journal of Microscopy 170: 25-33.

Dungan, C. F., AND B. S. Roberson. 1993. Binding specificities of mono- and polyclonal antibodies to the protozoan oyster pathogen, Perkinsus marinus. Diseases of Aquatic Organisms 15: 9-22.

Elandalloussi, L. M., R. M. Leite, R. Afonso, P. A. Nunes, J. A. Robledo, G. R. Vasta, and M. L. Cancela. 2004. Development of a PCR-ELISA assay for diagnosis of Perkinsus marinus and Perkinsus atlanticus infections in bivalve molluscs. Molecular and Cellular Probes 18: 89-96.

FisHeR, W. S., AND L. H. Oliver. 1996. A whole-oyster procedure for the diagnosis of Perkinsus marinus disease using Ray's fluid thioglycollate culture medium. Journal of Shellfish Research 15: 109117.

FORD, S. E., AND M. R. TRIPP. 1996. Diseases and defense mechanisms. In The eastern oyster Crassostrea virginica, R. I. E. Newell, V. S. Kennedy, and A. F. Eble (eds.). Maryland Sea Grant College, College Park, Maryland, p. 581-660.

García-Fiñana, M., L. M. Cruz-Orive, C. E. Mackay, B. PakKenberg, AND N. ROBERTS. 2003. Comparison of MR imaging against physical sectioning to estimate the volume of human cerebral compartments. Neuroimage 18: 505-516.

GAUTHIER, J. D., AND W. S. Fisher. 1990. Hemolymph assay for diagnosis of Perkinsus marinus in oysters Crassostrea virginica. Journal of Shellfish Research 9: 367-372.

C. R. Miller, AND A. E. Wilbur. 2006. Taqman (R) MGB real-time PCR approach to quantification of Perkinsus marinus and Perkinsus spp. in oysters. Journal of Shellfish Research 25: 619624.

GUNDERSEN, H. J. G. 1986. Stereology of arbitrary particles. A review of unbiased number and size estimators and the presentation of some new ones, in memory of Willian R. Thompson. Journal of Microscopy 143: 3-45.

Howard, C. V., AND M. G. ReED. 1998. Unbiased stereology. BIOS Scientific Publications, Oxford, U.K., 246 p.

Lowe, D. M., N. M. MoORE, AND B. L. BAYNE. 1982. Aspects of gametogenesis in the marine mussel Mytilus edulis L. Journal of the Marine Biological Association of the United Kingdom 62: 133145.

MACKIN, J. G. 1951. Histopathology of infection of Crassostrea virginica (Gmelin) by Dermocystidium marinum Mackin, Owen, and Collier. Bulletin of Marine Science of the Gulf and Caribbean 1: $72-87$.

Malpica, N., A. Santos, A. Tejedor, A. Torres, M. Castilla, P. García-BarReno, AND M. DEsco. 2002. Automatic quantification of viability in epithelial cell cultures by texture analysis. Journal of Microscopy 209: 34-40.

$\rightarrow$ Marsh, A. G., J. D. Gauthier, AND G. R. Vasta. 1995. A semiquantitative PCR assay for assessing Perkinsus marinus infections in the eastern oyster, Crassostrea virginica. Journal of Parasitology 81: $577-583$.

MatTFeldT, T., H. Frey, AND C. Rose. 1993. Second-order stereology of benign and malignant alterations of the human mammary gland. Journal of Microscopy 171: 143-151.

MAYHEW, T. M., AND H. J. G. GUNDERSEN. 1996. 'If you assume, you can make an ass out of $u$ and me': A decade of the disector for stereological counting of particles in 3D space. Journal of Anatomy 188: $1-15$.

McNulty, V., L. M. Cruz-Orive, N. Roberts, C. J. Holmes, AND X.
GuAL-ARNAU. 2000. Estimation of brain compartment volume from MR Cavalieri slices. Journal of Computer Assisted Tomography 24: 466-477.

MDTAO (MANUAL OF DIAGNOSTIC TESTS FOR AQUATIC ANIMALS). 2003. http://www.oie.int.

Michel, R. P., AND L. M. CruZ-Orive. 1988. Application of the Cavalieri principle and vertical sections methods to lung: Estimation of volume and pleural surface area. Journal of Microscopy 150: 117-136.

Morvan, C., AND A. D. ANSEll. 1988. Stereological methods applied to reproductive cycle of Tapes rhomboides. Marine Biology 97: 355-364.

Newell, R. J. E., T. J. Hilbish, R. K. Koehn, and C. J. Newell. 1982. Temporal variation in the reproductive cycle of Mytilus edulis (Bivalvia, Mytilidae) from localities on the East Coast of the United States. The Biological Bulletin 162: 229-310.

Nickens, A. D., J. F. La Peyre, E. S. Wagner, ANd T. R. Tiersch. 2002. An improved procedure to count Perkinsus marinus in Eastern oyster hemolymph. Journal of Shellfish Research 21: 725-732.

Pache, J. C., N. Roberts, P. Vock, A. Zimmermanns, and L. M. CruzORIVE. 1993. Vertical LM sectioning and parallel CT scanning designs for stereology: Application to human lung. Journal of $\mathrm{Mi}-$ croscopy 170: $9-24$.

Pakkenberg, B., AND H. G. J. Gundersen. 1988. Total number of neurons and glial cells in human brain nuclei estimated by the disector and the fractionator. Journal of Microscopy 150: 1-20.

Paulet, Y. M., G. Dorange, J. C. Cochard, and M. Le Pennec. 1992. Reproduction et recrutement chez Pecten maximus L. Annales de l'Institut Oceanographique 68: 45-64.

Pazos, A. J., G. Román, C. P. Acosta, M. Abad, and J. L. Sánchez. 1996. Stereological studies on the gametogenic cycle of the scallop. Pecten maximus, in suspended culture in Ria de Arousa (Galicia, NW Spain). Aquaculture 142: 119-123.

Penna, M. S., M. Khan, AND R. A. French. 2001. Development of a multiplex PCR for the detection of Haplosporidium nelsoni, Haplosporidium costale and Perkinsus marinus in the eastern oyster Crassostrea virginica (Gmelin, 1791). Molecular and Cellular Probes 15: 385-390.

PIPE, R. K. 1985. Seasonal cycles in and effects of starvation on egg development in Mytilus edulis. Marine Ecology Progress Series 24: 121-128.

RAY, S. M. 1952. A culture technique for the diagnosis of infections with Dermocystidium marinum. Mackin, Owen, and Collier, in oysters. Science 166: 360-361.

. 1954. Biological studies of Dermocystidium marinum, a fungus parasite of oysters. The Rice Institute Pamphlet, Special Issue, Houston, Texas, $114 \mathrm{p}$.

RemaCha-Triviño, A. 2002. Estereología Moderna y Anatomía de los espacios de referencia, tejido hemolinfático y aparato excretor de la especie Solen marginatus (Mollusca: Bivalvia). Interacciones fisiopatológicas del nefridio en relación al desarrollo del ciclo reproductivo. Ph.D. Thesis. Universidad de Oviedo, Oviedo, Asturias, $308 \mathrm{p}$.

Roberts, N., L. M. Cruz-Orive, M. K. Reid, D. A. Brodie, M. Bourne, AND R. H. T. EDWARDS. 1993. Unbiased estimation of human body composition by the Cavalieri method using resonance imaging. Journal of Microscopy 171: 239-253.

, A. S. Garden, L. M. Cruz-Orive, G. H. Whitehouse, and R. H. T. EDWARDs. 1994. Estimation of fetal volume by magnetic resonance imaging and stereology. The British Journal of Radiology 67: 1067-1077.

Robledo, J. A., J. D. Gauthier, C. A. Coss, A. C. Wright, AND G. R. VASTA. 1998. Species-specificity and sensitivity of a PCR-based assay for Perkinsus marinus in the eastern oyster, Crassostrea virginica: A comparison with the fluid thioglycollate assay. Journal of Parasitology 84: 1237-1244.

Romestand, B., J. TORReilles, AND P. RoCh. 2001. Production of monoclonal antibodies against the Protozoa, Perkinsus marinus: Estimation of parasite multiplication in vitro. Aquatic Living Resources 125: 323-329.

Saltykov, S. A. 1958. Stereometric metallography. State Publishing House for Metals and Sciences, Moscow, Russia, $446 \mathrm{p}$. 
SCHERLE, W. 1970. A simple method for volumetry of organs in quantitative stereology. Mikroskopie 26: 57-60.

SteIN, J. E., AND J. G. MACKIN. 1957. An evaluation of the culture method used in determining the intensity of Dermocystidium marinum in the oyster $C$. virginica. Texas A\&M Research Foundation, Technical Report 22: 1-5.

STERIO, D. C. 1984. The unbiased estimation of number and sizes of arbitrary particles using the disector. Journal of Microscopy 134: 127-136.

SundeT, J. H., AND J. B. LEe. 1984. Seasonal variations in gamete development in the Iceland Scallop Chlamys islandica. Journal of the Marine Biological Association of the United Kingdom 64: 411416.

Sunila, I., R. M. Hamilton, AND C. F. DungaN. 2001. Ultrastructural characteristics of the in vitro cell cycle of the protozoan pathogen of oysters, Perkinsus marinus. Journal of Eukaryotic Microbiology 48: $384-361$.

, AND J. LaBanCA. 2003. Apoptosis in the pathogenesis of in- fectious diseases of the eastern oyster Crassostrea virginica. Diseases of Aquatic Organisms 56: 163-170.

Villalba, A., K. S. Reece, M. C. Ordas, M. C. Casas, and A. FiGUERAS. 2004. Perkinsosis in molluscs: A review. Aquatic Living Resources 17: 411-432.

Weibel, E. R. 1979. Stereological methods. Vol. I: Practical methods for biological morphometry. Academic Press, London, U.K., 415 p.

West, M. J., L. SlomianKa, AND H. J. G. Gundersen. 1991. Unbiased stereological estimation of the total number of neurons in the subdivisions of the rat hippocampus using the optical fractionator. The Anatomical Record 231: 428-497.

Yarnall, H. A., K. S. Reece, N. A. Stokes, and E. M. Burreson. 2000. A quantitative competitive polymerase chain reaction assay for the oyster pathogen Perkinsus marinus. Journal of Parasitology 86: 827-837.

Young, D., C. A. Glasbey, A. J. Gray, and N. J. Martin. 1998. Towards automatic cell identification in DIC microscopy. Journal of Microscopy 192: 186-193. 